\title{
The Use of Adverbial Conjuncts of Chinese EFL Learners and Native Speakers-Corpus-based Study
}

\author{
Yuting Xu \\ Beijing University of Technology, Beijing, China \\ Email: tianaxyt@yahoo.cn \\ Yuhui Liu \\ Beijing University of Technology, Beijing, China
}

\begin{abstract}
This paper presents the difference about the use of adverbial conjuncts between Chinese EFL learners and native speakers. The learners' corpus CLEC and the native speakers' corpus LOB have been used. Statistics and Chi-square test value demonstrate that Chinese EFL learners tend to overuse, underuse, and inappropriately use conjuncts compared with native speakers. They prefer to use a rather small set of conjuncts, such as listing conjuncts. Besides, Chinese EFL learners have a tendency to place the conjuncts in initial position, while native speakers prefer the medial position. The way that Chinese EFL learners emphasize on structure rather than content may cause the overuse of conjuncts, and limited exposure to those conjuncts may lead to the singleness of their positions.
\end{abstract}

Index Terms—adverbial conjuncts, corpus, statistics, overuse, position

\section{INTRODUCTION}

There is a common phenomenon among Chinese English learners that they always have some difficulties in using adverbial conjuncts. In this way, their expression and communication may not be logical enough comparing to native speakers. As a result, their essays and speeches tend to be unpersuasive and unorganized in some cases.

One possible cause for that are the overuse, underuse, and inappropriate use of adverbial conjuncts. The problem for Chinese EFL learners is not that they avoid using adverbial conjuncts, but their choices of those conjuncts are rather limited in that learners are not familiar with some words, whereas they are too familiar with other "universal" words. Particularly, we may notice that some listing conjuncts frequently appear while we use English. Besides, the position of those conjuncts within sentences is also worthy to be discussed. Therefore, this paper will find out those adverbial conjuncts that Chinese EFL learners prefer to use, and then to see if there is any difference in the use of them, compared to the way native speakers do. Furthermore, the present study will compare the position of certain conjuncts within sentence between learners and native languages users. Corpus will be used to find evidence for such differences, thereby revealing the problems that learners have when using those adverbial conjuncts.

CLEC and LOB are chosen as the comparing corpora for this study; analysis with statistics will be given and shown to prove the result of comparison. Reasons for the comparing results will be explored, and finally, suggestions will be given in accordance with the problems that Chinese EFL learners might have when using adverbial conjuncts.

\section{STUdy OF AdVERBial CONJUNCTS}

\section{A. Definition of Adverbial Conjuncts}

In previous study, several alternative terms about adverbial conjuncts have been used, for instance, "conjunctive adverbials" (Wei-yu Chen, 2006, p. 113) or "conjuncts" (Quirk et al, 1985, p. 6). In English, adverbials most commonly take the form of adverbs, adverb phrases, temporal noun phrases or prepositional phrases. In every sentence pattern, the adverbial is a clause element that tells where, when, why, or how. There can be more than one adverbial in a sentence. In addition, the same adverbial can be moved to different positions in a sentence. Adverbial conjuncts make up an even stronger category of conjuncts. They "conjoin linguistic units, such as sentences, paragraphs and even large parts of a text" (Quirk et al, 1985, p.7). Hence they show logical relationships between two independent sentences, between sections of paragraphs, or between entire paragraphs. They are one word items or fixed word combinations, which contribute to the clarity and comprehensibility of a text.

\section{B. Classification of Adverbial Conjuncts}

Grammarians and linguists have carried out many different classifications of adverbial conjuncts. Biber et al (1999) and Quirk et al (1985) are two prominent figures in this field, who all have a broad definition of epistemic modality but 
delimit the category slightly differently. This study resorts to the classification of Quirk et al's, which divides adverbial conjuncts on the basis of their semantic functions. Here is the list of the category.

TABLE1

ClASSIFICATION OF ADVERBIAL CONJUNCTS

\begin{tabular}{|l|l|}
\hline Semantic roles & Concrete words \\
\hline Listing & $\begin{array}{l}\text { First(ly), second(ly), third(ly), in the first/second/third place, first of all, to begin with, next, then, finally, last(ly), } \\
\text { last of all, in addition, additionally, and, similarly, likewise, further (more), besides, also, moreover, equally, } \\
\text { correspondingly, in the same way, what's more, above all, for one thing... for another (thing) }\end{array}$ \\
\hline Summative & $\begin{array}{l}\text { in sum/summary/conclusion, summing up, to sum up, to summarize/conclude, in all, all in all, overall, } \\
\text { (al)together, in brief, in short, briefly, generally (speaking), in general, so far, thus, therefore, on the whole }\end{array}$ \\
\hline Appositive & $\begin{array}{l}\text { That is (to say), i.e., in other words, namely, (more) specifically, particularly, in particular, for example, e.g., for } \\
\text { instance, or rather }\end{array}$ \\
\hline Resultive & $\begin{array}{l}\text { Consequently, as a/in consequence, hence, so, therefore, thus, as a result, in turn, somehow, subsequently, else, } \\
\text { then, finally, eventually, in other words }\end{array}$ \\
\hline Inferential & Accordingly, in that case, in this way, perhaps, by the same token, otherwise \\
\hline Contrastive & $\begin{array}{l}\text { However, on the other hand, rather (than), alternatively, conversely, on the contrary, in/by contrast, by the way of } \\
\text { contrast/comparison, in comparison, nevertheless, nonetheless, notwithstanding, (al)though, yet, but, in spite of } \\
\text { that, all the same, despite, unfortunately }\end{array}$ \\
\hline Transitional & $\begin{array}{l}\text { By the way, in the meantime, instead (of), anyhow, anyway, still, in any case/event, at any rate, after all, at the } \\
\text { same time, at all events, needless to say, admittedly }\end{array}$ \\
\hline
\end{tabular}

The above list of words, nevertheless, is not an absolute classification of adverbial conjuncts. One matter that can make the analysis of certain semantic roles problematic is that some of the conjuncts can be listed under several roles. For instance, the word thus can be listed under summative, appositive and resultive roles depending on the context (Quirk et al. 1985, p. 365-p. 368). Since these roles share some features and are semantically connected, the exact classification of the connector might in some cases be difficult. Yet this paper aims to discover the overall use of adverbial conjuncts, thus accurate clarification of each certain word is not necessary in this study.

\section{Methodology}

\section{A. Corpus, Instrument and Measurement}

The corpus materials used in the present study are CLEC and LOB. CLEC contains 1 million words of English compositions collected from Chinese learners of English with differing levels of proficiency, covering senior secondary school students, English-major, and non-English-major university students in China. The LOB Corpus (Lancaster-Oslo-Bergen Corpus) was compiled in 1980s in collaboration between the University of Lancaster, the University of Oslo, and the Norwegian Computing Centre for the Humanities, Bergen. With an amount of 1 million words, LOB is used as the reference corpus.

The study takes WordSmith 5.0 as instrumentation, to test the frequency of each adverbial conjunct. Top used conjuncts of both corpora will be listed.

To be more specific, raw frequency data will be examined in this research, to see how often a certain conjunct occurs in both the learner corpus and the native corpus. The calculating data will provide a general view about which category of conjuncts are most frequently used by native speakers and Chinese learners respectively. By comparison, afterwards, statistics will help to find out which conjuncts are particularly overused or underused by Chinese learners. Moreover, the position of those conjuncts that Chinese students prefer to use the most will be presented; three variants have been distinguished: initial, medial and final position. In comparison with native language users, the paper will judge whether learners have appropriately used those conjuncts depending on the percentage of occurrences.

Chi-square Test will be used to show the comparing result between the two corpora, so as to describe the possible differences. It will provide evidence to prove whether the observed difference is statistically significant.

\section{B. Research Questions}

The purpose of this study is to present a quantitative analysis of the conjuncts used by Chinese students. The research questions examined in the study are:

a. Are there any differences in the use of adverbial conjuncts between Chinese and native speakers? How do they differ from each other?

b. Compared to native speakers, do Chinese learners overuse or underuse certain conjuncts?

c. Do Chinese learners place the conjuncts in the same positions in sentences as native speakers?

\section{RESUlt AND DisCUSSION}

\section{A. General Use of Adverbial Conjuncts}

Since the total numbers of the two corpora are approximate, the occurrence frequency is comparable. 
TABLE 2

TOTAL NUMBER OF WORDS IN CORPORA/CONJUNCT TOKENS

\begin{tabular}{|c|c|c|}
\hline & CLEC & LOB \\
\hline Overall tokens (running words) & $1,273,080$ & $1,222,586$ \\
\hline Total number of conjunct tokens & 12881 & 8476 \\
\hline
\end{tabular}

Table 2 reflects the overall use of adverbial conjuncts of both Chinese EFL learners and native speakers. In Chi-square test that the $p$ value is below 0.05 , therefore the difference in overall use is statistically significant. It is obvious that Chinese student use adverbial conjuncts more frequently than native speakers. Statistics demonstrate that there is a general tendency of overuse by the Chinese EFL learners. There are actually some overuse problems with adverbial conjuncts.

To have a more specific insight into the usage of each category, other statistical results, including frequency and Chi-square test results are shown in Table 3.

TABLE 3

CONJUNCTS USED ACCORDING TO CLASSIFICATION OF AC \& CHI-SQUARE TEST

\begin{tabular}{|l|l|l|l|l|}
\hline \multirow{2}{*}{ Semantic roles of AC } & \multirow{2}{*}{ CLEC } & \multirow{2}{*}{ LOB } & Chi $^{2}$ test \\
\cline { 3 - 5 } & & & $x^{2}$ \\
\hline Listing & 3764 & 1173 & 1259.972 & 0.0000 \\
\hline Summative & 971 & 824 & 6.832 & 0.0000 \\
\hline Appositive & 1138 & 742 & 68.237 & 0.0000 \\
\hline Resultive & 1342 & 1025 & 30.637 & 0.0000 \\
\hline Inferential & 486 & 533 & 4.490 & 0.0000 \\
\hline Contrastive & 3502 & 2980 & 23.638 & 0.0000 \\
\hline Transitional & 1678 & 1271 & 40.974 & 0.0000 \\
\hline
\end{tabular}

Notes: $\mathrm{AC}=$ Adverbial Conjuncts

Each of the computed $p$ value is significantly lower than the required value. Thus it is fair to say there is a general tendency for Chinese learners to overuse or underuse adverbial conjuncts compared with native English speakers. All the semantic categories are used more frequently in CLEC except for that inferential conjunct is the opposite.

In general, the overuse of adverbial conjuncts can be explained from three aspects. One is that Chinese EFL learners learn and use those conjuncts as grammatical markers rather than natural connectors. They are taught that articles without conjuncts are poorly organized and not logically complete. As a result, they tend to use them on purpose, as to reach some certain criteria or to follow some grammatical rules. Another is the exam-driven effect of Chinese education system. One way to judge the quality of learners' essay is the quantity of conjuncts especially the adverbial conjuncts. Standard of good article encourages students to use conjuncts as many as they can. Lastly, Chinese EFL learners are unable to use English as fluently as their mother tongue. Once they have some trouble in expressing, they would be willing to use more connectives and conjuncts for help, in order to give more explanation, make their sentence clearer.

The ranks of categories are similar in both CLEC and LOB, which suggests that Chinese EFL learners have the same habit as the native while they try to make their discourse well organized.

Now let's take a look at the differences between CLEC and LOB in each semantic category. Apparently, listing conjunct and contrastive conjunct are the most popular categories that learners prefer. In LOB however, contrastive conjunct and transitional conjunct rank the top two. Even though both learners and native speakers use contrastive conjuncts, the frequency in LOB is quite low compared to that in CLEC. A shaper difference is Chinese EFL learners' strong preference of using listing conjuncts. A quick check indicates that native speakers seldom use those conjuncts such as first, second, etc.

To explain the results, there are several notable perspectives. Most of the essay topics in CLEC are assigned by teachers or a certain committee which the students are not quite familiar with; moreover, these topics are mostly argumentative, which make it difficult for the student to maintain the content and the form of the essays in a logical order. In order to express their viewpoints explicitly in a limited time and in the context of exams, students use a lot contrastive conjuncts so that they can demonstrate more ideas to enrich their content. Meanwhile, students use more listing conjuncts than other conjuncts, so that their writings can be easily and explicitly arranged in a good order with the help of these listing conjuncts.

Nonetheless, the number of inferential conjuncts in CLEC is lower than that in LOB. Inferential conjuncts have the function of developing content, implicating themes, and elaborating ideas. Compared to native speakers, it seems that Chinese EFL learners are not good at developing further ideas or taking deeper insight.

\section{B. Individual Conjuncts}

The above analysis has already provided a general overview of the whole use of adverbial conjuncts. Next, the study will narrow down to focus on some individual conjuncts, which learners tend to overuse or underuse as compared with native speakers, so as to discover features characteristic of Chinese learners' use of English adverbial conjuncts. 
TABLE 4

TOP TEN CONJUNCTS USED IN THE CORPUS

\begin{tabular}{|l|l|l|l|}
\hline CLEC & $n$ & LOB & $n$ \\
\hline But & 1609 & But & 1052 \\
\hline For example & 865 & Though & 601 \\
\hline First & 760 & However & 548 \\
\hline However & 690 & Rather & 397 \\
\hline Though & 606 & Although & 365 \\
\hline Second & 473 & Therefore & 289 \\
\hline although & 327 & Then & 297 \\
\hline Secondly & 317 & Thus & 250 \\
\hline Therefore & 312 & Particularly & 229 \\
\hline Then & 295 & Finally & 159 \\
\hline
\end{tabular}

From the result we can see that Chinese learners rely too much on some certain conjuncts, such as but, however, though and so on. Among the top 10, for instance, first, second, secondly and for example didn't appear in those of the native speakers. The difference exposes the feature of Chinese student's writing. 3 of the 4 are listing conjuncts, suggesting listing category is frequently used. We may conclude that Chinese learners like to list their ideas one by one, in stead of making some logical connection when they shift to other thoughts. Listing words help learners to list facts or reasons together and put them in ordinal position. By using such words, it can be easier for learner to organize their article, and make ideas seemingly relative.

Besides, Chinese EFL learners tend to use a certain set of words they are familiar with, and avoid using some unfamiliar words which native speakers use a lot, such as rather, particularly, thus and so on. This might be explained by the fact that learners have used a smaller and less varied range of conjunct types, or they have tended to avoid using certain conjuncts in which they had less confidence due either to their lack of understanding of the abstract meaning of some items or their inexperience in using them. This result suggests that we are still beyond an idiomatic level. Among the above list, the three words which did not rank into top 10 in CLEC (rather, particularly, thus) reflects the different habit between learners and native speakers in organizing ideas. The word rather is used to express a preference or to say what you want to happen; particularly is used to emphasis certain point; thus indicates the coming of conclusion. These adverbial conjuncts make articles more logics and integrated compare to those listing words.

Since the corpora provide differences of the choice of adverbial conjuncts and LOB is a collection of authentic essay of native use of English, it should arouse more attention in the using of words that learners are not that familiar with. Those high frequency words might learners' essays more idiomatic.

\section{Position of Conjuncts}

In English, many connectors can have a changeable position in clauses and sentences. Even though the clause initial position is the norm for most connectors, some connectors are common in medial position (e.g. however) or final position (e.g. anyway) (Quirk et al, 1985). Since 6 words (but, however, though, although, therefore, then) in top 10 are the same in the two corpora (except for slight ranking difference), only the clause position of these 6 conjuncts is examined in the current study. Three variants have been distinguished: initial, medial and final position. Table 5 shows the position of the conjuncts in the learner corpus and the native corpus.

TABLE 5

POSITION OF CONJUNCTS IN CLEC \& LOB

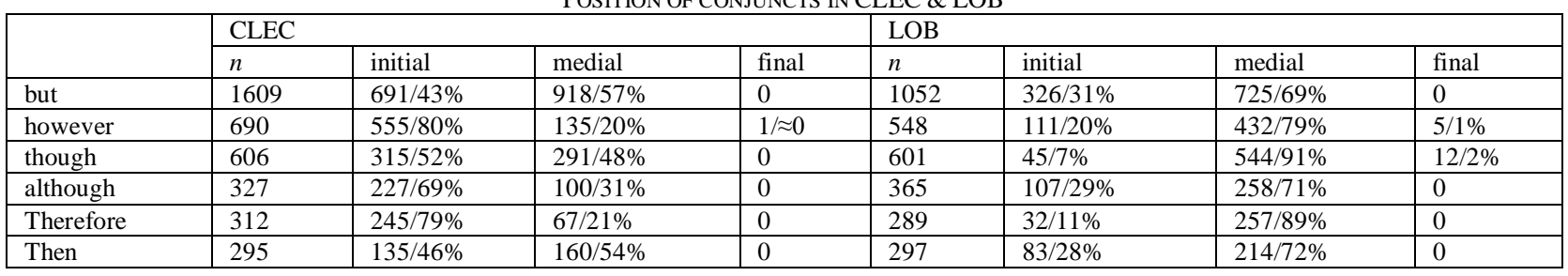

Most time conjuncts rarely show up at the end of sentences. But we can see that words like however and though can be put in the end of sentences. In consequence, conjuncts do not only appear at the beginning and in the middle of sentences.

The main finding according to the above table is: Chinese EFL learners prefer the clause-initial pattern when using conjuncts. Take however as an example, $80 \%$ of it is in initial position while $20 \%$ is in medial in CLEC, whereas in LOB $20 \%$ of it is in initial but $79 \%$ is in medial. The percentage of the initial position is always higher than the medial in CLEC, but displays conversely in LOB. As a result, there is a tendency for learners to place conjuncts initially. The percentage shows, however, native speaker usually put conjuncts in the middle of sentence. The results should arouse our attention about the position of conjuncts.

The comparing results can be explained in the following perspectives: in one term, learners acquire the meaning of those adverbial conjuncts first but not the ability of using it. Contrastively, native speakers acquire such vocabulary at a rather young age, thus they use those conjuncts more smoothly and naturally. In comparison, Chinese EFL learners' 
flexibility of using adverbial conjuncts is lower than that of native speakers. In another term, learners might be more careful while putting those conjuncts into their sentence, whereas native speakers are more confident. Therefore the position of adverbial conjuncts is more variable in LOB than in CLEC.

\section{CONCLUSIONS}

\section{A. Major Findings}

This paper has offered a quantitative analysis of how Chinese learners use conjuncts. The overall results show that Chinese learners tend to overuse conjuncts than the native speakers do. There are also some differences in the usage of individual conjuncts between the learners and the native speakers. The comparing result indicates that Chinese EFL learners rely on a rather small set of conjuncts in their use of the language. The learners have a preference of using listing and contrastive conjuncts. In contrast, a quick test shows native speakers use fewer listing conjuncts. In the case of the top six most frequently used conjuncts, Chinese EFL learners have a tendency to place the conjuncts in initial position, while native speakers prefer the medial position in a sentence.

As for the reasons, a highly relevant one is that Chinese English teaching always focus on the organization and structure in fostering writing ability rather than developing thinking ability. In consequence, learners are willing to choose simple and clear connectors to directly illustrate their ideas one after another. In another term, the vocabulary of EFL learners is rather limited. They might be confused by the meaning of adverbial conjuncts, let along the use of it. Hence, listing and contrastive conjuncts are easier to understand and master. Besides, genre of the article in CLEC has limited students' choice of words. Most of the articles in CLEC are collected from the CET tests. Affected by the marking standard, learner will pay more attention to the connection, structure, and language fluency instead of the content. Therefore, adverbial conjuncts can be use to modify their article so as to cover the inefficiency of the content, owing to the fact that conjunct firstly can connect sentences and paragraphs, secondly can help to build up a well-organized article. These all contribute to the facts that conjuncts are more frequently used by learners than natives.

\section{B. Pedagogical Implication}

Chinese EFL learners, even advanced learners, overuse, underuse, or inappropriately us adverbial conjuncts. Such phenomenon directly results in disjoin, illogical and lacking of reader consideration writings of nonnative English speakers. Given that there is a connection between a writer's use of connectives and a reader's perception of a text as being cohesive and persuasive, it follows that EFL learners' writing could be improved by instructions on the use of conjuncts.

On the basis of the above analysis, we can work out several ways to improve the phenomenon of overuse and inappropriate use of adverbial conjuncts. On one hand, learners' writing could be improved by instructions on the use of conjuncts; more adverbial conjuncts should be acquired. It must be made explicit to students that cohesion does not result from simply scattering large numbers of conjuncts and other categories of cohesive devices all over the text. Students should learn how connectives, only when used aptly and selectively, can signal different types of logical and conjunctive relations between sentences or propositions.

In other words, EFL learners should place more emphasis on how to use conjuncts correctly and effectively. Instead of putting most of the adverbial conjuncts in the initial position, they have more than just one way of use. From a broader horizon, English study can also include some thinking training, instead of focusing only on language patterns. On the other hand, we can view more original writings, so as to get familiar with the flexible use of adverbial conjuncts, about where they usually appear in sentences. In these ways, we can be more creative in English writing, getting use to a new thinking style, and use adverbial conjuncts more idiomatically.

\section{Limitation and Suggestion}

The investigation of this study has been restricted to a manageable range of adverbial conjuncts; hence the number of adverbial conjuncts is not exhaustive, only the top 10 has been focused on in the present study.

It has to be mentioned here that statistics in table 5 are manually collected, so there might be some statistical errors when it comes to the actual number, but the data round off the percentage, which means the comparing result is reasonable.

What's more, more authentic data might be more precise, since CLEC is a rather restricted corpus according to its source. From this perspective, it is advisable for researchers to make efforts to collect authentic and natural language for further research.

\section{ACKNOWLEDGEMENTS}

Here extending my greatest thankfulness to my advisor, professor Yu-hui Liu, a respectable, responsible and resourceful scholar. It is she who enlightens my study of applied linguistics and my research related to this field. She has provided me with valuable guidance in every stage of the writing of this thesis. Her keen and vigorous academic observation inspires me not only in this thesis but also in my future study. Her guidance and supervision directly contribute to the accomplishment of this academic investigation. 
My sincere appreciation also goes to professor Nai-xing Wei, who has helped in broadening my horizon of knowledge in corpus study and offers me advices, and helps me to develop the fundamental and essential academic competence.

\section{REFERENCES}

[1] Biber, D. (1995). Dimensions of Register Variation: A Cross-linguistic Comparison. Cambridge: Cambridge University Press.

[2] Biber, D., S. Conrad \& R. Reppen (1998). Corpus Linguistics: Investigating Language Structure and Use. Cambridge: Cambridge University Press.

[3] Curzan, Anne; Adams, Michael. (2009).How English Works: A Linguistic Introduction (2nd ed.), New York: Pearson Longman

[4] Frawley, W. \& J. P. Lantolf. (1985). Second language discourse: A Vygotskyan perspective. Applied Linguistics 6/1: p. 18-p. 43.

[5] Sinclair, J. (1991). Corpus, Concordance, Collection. Cambridge: CUP.

[6] Skehan, P. (1998). A Cognitive Approach to Language Learning. Oxford: Oxford University Press.

[7] Quirk, R., S. Greenbaum, G. Leech \& J. Svartvik. (1985). A Grammar of Contemporary English. London: Longman. P. 6-p. 7

[8] Wei-yu Chen, C. (2006). The use of conjunctive adverbials in the academic papers of advanced Taiwanese EFL learners. International Journal of Corpus Linguistics, 11(1), p. 113-p. 130.

[9] Zhang Xuemei. (2007). A corpus-based study on Chinese EFL learners' use of adverbial conjuncts. CEL EA Journal, Vol 30, No.2. p. 34

Yuting Xu was born in Beijing, China in 1988. She received her B.A degree in English from Beijing University of Technology in 2010.

She is currently a graduate student in College of Foreign Languages, Beijing University of Technology, majoring in applied linguistics. Her main interests include language teaching and Functional Grammar.

Yuhui Liu is a professor in College of Foreign Languages, Beijing University of Technology and has published more than 30 academic papers on English teaching \& learning and on conversational analysis, and more than 20 textbooks and workbooks on vocabulary, listening, reading and writing as the first author or chief editor; she has been in charge of more than 10 academic research projects about teaching methodology, teaching reform, and conversational analysis \& teaching of listening and speaking. 